\title{
Verena Dolle
}

\section{Autorretratos. \\ Las relaciones entre imagen y texto en Las genealogías de Margo Glantz}

\section{Introducción}

Dentro de la pluralidad de voces judías latinoamericanas, quisiera dirigir la atención hacia la autobiografía como género literario, que siempre resonó en las presentaciones y discusiones del simposio, aun cuando hasta ahora sólo se haya abordado un texto verdaderamente autobiográfico: On Borrowed Words (2001) de Ilan Stavans, obra que constituye, en cierta medida, un caso especial por ser redactada en una lengua extranjera recién aprendida. Sin embargo, ya se han discutido varias novelas que tienen cierto tinte autobiográfico, como Los dolientes (2004) de Jacobo Sefamí, Bosque quemado (2007) de Roberto Brodsky, Poste restante (2001) de Cynthia Rimsky, El árbol de la gitana (1997) de Alicia Dujovne Ortiz y Lenta biografia (1990) de Sergio Chejfec. ${ }^{1}$ La misma Ana María Shua nos ha permitido echar un vistazo a su taller de escritora, poniendo así de relieve el atractivo, los retos y las trampas de lo supuestamente verdadero, lo autobiográfico que la ha llevado -así lo escribe- a optar finalmente por lo ficticio. ${ }^{2}$ Algo parecido sucedió, en el caso de Alicia Steimberg, con su primer libro, Músicos y relojeros (1971), que quizás, según la óptica adoptada, podría leerse, en cierto modo, como una autobiografía, pero más bien parece ser una novela autobiográfica. Sin embargo, esta dimensión autobiográfica referencial no desempeña el papel principal, sino que sólo constituye una parte del conjunto de la narración híbrida. No sería adecuado, e incluso erróneo, a mi parecer, leer los textos mencionados solamente bajo la óptica de lo autobiográfico y restar importancia al papel de la ficción.

1 Remito a los artículos de Rodrigo Cánovas, Amalia Ran y Katja Carrillo Zeiter en este mismo volumen.

2 Cf. su contribución en este mismo volumen. 
En lo que sigue, sin embargo, me propongo tratar esbozos de identidad en un texto explícitamente autobiográfico, que desempeña un papel de texto fundacional en la literatura judía latinoamericana de las últimas décadas y representa un verdadero hito en cuanto a la visibilidad de la literatura judía de este periodo: Las genealogías (1981) de Margo Glantz. Su objetivo expresamente declarado es el de autoasegurarse de la pertenencia del individuo a varios grupos que constituyen su identidad cultural: familia, etnia (los judíos), nación (mexicana), género. Tomo como punto de partida las discusiones recientes sobre conceptos de identidad que conciben al sujeto de la segunda mitad del siglo XX como descentrado, fragmentado, discontinuo, constituido de varias, a veces contradictorias identidades (Hall 2008: 182) -yo añadiría: múltiples-, Ahora, se destaca el aspecto dinámico, inacabado, constructivo del proceso de formación de la identidad, contrario a ideas anteriores que entendían al sujeto de una manera esencialista, de varias características invariables, incluso supuestamente "naturales". Dice Stuart Hall: "El sujeto es definido histórica no biológicamente" (2008: 183; mi trad., V. D.). Este sujeto entra en relación con varios grupos relevantes para su identidad cultural: en lo que concierne a nación, etnia, religión, incluyendo siempre el aspecto del género como factor influyente (Hall 2008: 198).

Aquello que se hace pasar como esencialista, como carácter inmutable para mantener unida una comunidad (imaginada), se revela como una construcción que obedece a determinadas estrategias: narración y acentuación de un origen común, invención de continuidad y una tradición intemporal, un carácter, pues, invariable; además, se ve acentuada a menudo la idea de la pureza del colectivo en cuestión (Hall 2008: 201-203, sobre la cultura nacional como comunidad imaginada). En Gender trouble, Judith Butler ha reforzado aún esta concepción constructivista, anti-esencialista de la formación de la identidad al ver incluso las diferencias biológicas, supuestamente "naturales" de los géneros como producidas performativamente a través de una actuación repetida. ${ }^{3}$

A continuación me dedicaré a la cuestión qué esbozos de identidad (esencialistas o constructivistas) se dan en Las genealogías de Margo

3 Ver Butler (1991: 198-209) donde ella desarrolla detenidamente esta idea de la fabricación de una identidad de género. 
Glantz. Me concentraré particularmente en la relación que se desarro1la entre las fotografías intercaladas y el texto. Quisiera demostrar que, más allá de una función ilustradora de las fotografías, éstas abren un nuevo espacio interpretativo en la construcción de la identidad mediante su integración en la escritura. A diferencia de María Eugenia Mudrovcic, que atribuye a las fotografías un carácter de "segundas en visibilidad después de la narración", ${ }^{4}$ pienso que en el diálogo entre las fotografías y el texto se negocian cuestiones de identidad. En lo que sigue, abordaré primero brevemente el desarrollo del género literario de la autobiografía, desde su forma tradicional hasta la así llamada "nueva autobiografia", así como rasgos específicos de la autobiografía femenina. Después me detendré en la caracterización de la relación entre texto e imagen, más concretamente entre autobiografía y fotografía, medios que han recorrido una historia paralela, incluso entangled (Randeria) en lo que toca a la supuesta referencialidad y veracidad de ambas. En seguida, me dedicaré a la obra de Margo Glantz y me focalizaré en cómo se tematiza la identidad (cultural) en el texto y las fotografías respecto a la relación entre el individuo y la comunidad -familia, etnia, nación-, y finalmente, qué concepción de identidad en general se deja (entre)ver en Las genealogías.

\section{Autobiografía con atributos: tradicional - nueva - femenina}

Sabemos que la literatura autobiográfica femenina latinoamericana ha ido desarrollándose considerablemente en las últimas cuatro décadas. Aún en 1962, la crítica brasileña Tania Regina Oliveira Ramos lamenta la ausencia casi total de literatura autobiográfica femenina y la dominación de este género por manifestaciones masculinas. A partir de los años 70 del siglo pasado se puede notar en general un incremento notable de los textos autobiográficos femeninos en Latinoamérica, como lo ha destacado Regina Igel (1999: 62). Cabe recordar que Elisa Lispector, hermana de Clarice, con No exílio de 1948 se vuelve una de las primeras autoras latinoamericanas judías que transmiten una visión de los inmigrantes judíos en territorio brasileño desde una perspectiva femenina, y con esto llevó a cabo una contribución importante a la

4 Mudrovcic (2003: 49); con una excepción significativa, que mencionaré más adelante (nota 38 ). 
literatura brasileña judía. ${ }^{5} \mathrm{El}$ hecho de que ella no haya optado por una autobiografía en sentido clásico, sino por una novela autobiográfica, podría deberse a varias razones: mi hipótesis al respecto es que, por un lado, a diferencia de una novela, una autobiografía judía, y además femenina, hubiera estado fuera del discurso hegemónico de la época y, por consiguiente, sin autoridad suficiente; por otro lado, la ficción ofrece más posibilidades de tematizar experiencias traumatizantes. ${ }^{6}$

A partir de los años 70 del siglo XX se da un aumento general de las publicaciones de textos de tinte autobiográfico escritos por mujeres y, entre ellos, los de mujeres judías. Así lo nota Marjorie Agosín, poeta e investigadora chilena de origen judío (Agosín 1999b: xix). Este auge del género se produce con la boga del feminismo y la conciencia creciente de oponerse a un discurso masculino dominante, y debe verse en el contexto más global de un interés en aumento por los grupos marginados y las manifestaciones directas de voces subalternas y suprimidas no mediadas por cualquier representante (como lo manifiesta, por ejemplo, la novela testimonio, Agosín 1999b: xix).

El incremento de textos autobiográficos viene acompañado de tendencias de hibridación fundamentales en relación al género literario. En su obra básica sobre la autobiografía tradicional, Le pacte autobiographique (1975), Philippe Lejeune la había podido definir todavía -quizás ya en reacción a estos fenómenos percibidos como disolución- como "relato retrospectivo en prosa que una persona real hace de su propia existencia cuando pone el acento sobre su vida individual, en particular sobre la historia de su personalidad" (Lejeune 1975: 14, mi traducción, V. D.). Lejeune postula una identidad ono-

5 Dentro del campo de la literatura brasileña, Frida Alexander, Janette Fishenfeld y Sara Riwka Ehrlich son autoras más tardías que Elisa Lispector, con novelas y cuentos (que tienen cierto tinte autobiográfico) publicados a partir de los años 60 . Sin embargo, no han obtenido gran resonancia pública, como lo destaca Regina Igel (1999: 72-82).

6 Dolle (2010: 99-102). Cabe mencionar aquí el trabajo de Lanser, quien dirige su atención hacia los géneros literarios accesibles a mujeres en momentos dados: "[...] what forms of voice have been available to women, and to which women, at particular moments. My intention is to explore through specifically formal evidence the intersection of social identity and textual form, reading certain aspects of narrative voice as a critical locus of ideology. [...]. It is my hypothesis that gendered conventions of public voice and of narrative self-reference serve important roles in regulating women's access to discursive authority" (Lanser 1992: $15)$. 
mástica bien marcada entre autor (cuyo nombre está en la cubierta del libro), narrador y personaje principal del texto, de modo que el lector tiene la "garantía" de leer algo verdadero, no-ficticio, lo que él llama el "pacto autobiográfico". Sin embargo, a pesar de ese pacto y el carácter referencial determinante del género reivindicados por Lejeune, se tiende hacia la permeabilidad de las fronteras entre ficción y facticidad. Con ello, desde los años 70 del siglo XX se vuelve obsoleta esta definición para la mayoría de los textos autobiográficos. Se lleva a cabo una mezcla entre referencialidad y ficcionalidad, se recurre conscientemente a elementos ficticios, juegos con roles y figuras (en parte provenientes de las propias obras de ficción), lo que ha llevado a la crítica a hablar de la "nueva autobiografía".

Los textos que han sido denominados con el concepto de "nueva autobiografía", llamados también autofiction (Serge Doubrovsky) y "autohistoria" (Gloria Anzaldua), socavan y transgreden los límites de los géneros literarios ${ }^{7}$ y exponen el proceso mismo de creación y enunciación (De Toro/Gronemann (2004). Este desarrollo tiene que ver con el cambio del concepto de identidad y la formación del individuo (así como con el proceso de recordar) y, por consiguiente, con un cambio de objetivo en la escritura. Como consecuencia de esta comprensión (basada en las teorías psicoanalíticas de Freud y Lacan sobre las instancias del Yo y el Ello), se evidencia la imposibilidad de un esbozo coherente y lineal del Yo. El Yo, entendido por tanto ya no (más) como autónomo y con núcleo fijo o como esencia fija, ya no puede ser representado, en su aislamiento, de manera retrospectiva y lineal, sino cuando mucho solamente el intento de esa construcción del Yo. Así lo resumen Alfonso de Toro y Claudia Gronemann:

Las referencias biográficas y una resultante historia estructurada coherente no se encuentran en el centro de esta nueva escritura autobiográfica, sino más bien su descripción como estrategia discursiva y el acto de moldeo del material en una autobiografía (De Toro/Gronemann 2004: 8, mi traducción, V. D.).

Además, resulta pertinente mencionar los resultados de las investigaciones psicológicas y de las neurociencias sobre el proceso de recordar: se ha destacado que este proceso no funciona como el acceso a un

7 Remito al volumen de De Toro/Gronemann (2004) y de Gronemann et al. (2010), donde se tratan varias manifestaciones de la "nueva autobiografía" en literaturas romances. 
contenedor donde se conservan las memorias de modo invariable, estable, sino que más bien se trata de un proceso dinámico, donde la imaginación juega un papel importante; se lleva a cabo una construcción de las memorias que no es independiente de la situación actual de la persona que recuerda (Welzer 2002: 19-44).

La investigación más reciente de la autobiografía no sólo se ha ocupado de nuevas estrategias discursivas, sino también se ha preguntado si se pueden destacar aspectos específicos de género (gender) en ella. Sin pretender favorecer un pensamiento esencialista, resulta pertinente observar que la investigación ha puesto de relieve determinadas diferencias al respecto. Primeramente se ha demostrado que la definición del género autobiográfico propuesta por Lejeune, supuestamente neutral, es en el fondo una definición para un género dominado por individuos masculinos blancos y europeos (Watson/Smith 1992: xvii; sin embargo, cabe mencionar que incluso la idea de la "autobiografía masculina modelo" es una construcción demasiado unificadora).

Caren Kaplan (1992: 121) apunta que la forma de narrar de las autobiografías femeninas es diferente en tanto que utilizan a menudo una communal voice, es decir, una voz común o grupal, en lugar de un Yo solitario, utilizado con frecuencia por autores masculinos. ${ }^{8}$ Cabe destacar que esta communal voice no sólo se atribuye a autoras femeninas, sino también a miembros de una comunidad marginada o suprimida, que de esta manera intentan establecer una autoridad narrativa. Este aspecto de la valoración de la comunidad se relaciona con la representación de una red de relaciones que estos textos frecuentemente tematizan: las autoras sienten a menudo la necesidad de dar voz a sus padres y antepasados, y de construir una historia familiar colectiva que tiene también el objetivo de tomar conciencia de sus propias raí-

8 En su estudio narratológico sobre los modos de autorizar la narración, Lanser diferencia las instancias narrativas de voz autorial, voz personal y communal voi$c e$, caracterizando esta última de la siguiente manera: "[...] a practice in which narrative authority is invested in a definable community and textually inscribed either through multiple, mutually authorizing voices or through the voice of a single individual who is manifestly authorized by a community. [...] Unlike authorial and personal voices, the communal mode seems to be primarily a phenomenon of marginal or suppressed communities. I have not observed it in fiction by white, ruling-class men perhaps because such an ' $I$ ' is already in some sense speaking with the authority of the hegemonic "we" (Lanser 1992: 21). 
ces. ${ }^{9}$ En otras palabras: el sujeto-narrador investiga su anclaje en lo que constituye su identidad cultural y los elementos que forman parte de ella. En la teoría del género autobiográfico se habla de una orientación femenina hacia las relaciones sociales con su entorno, a diferencia de los individuos masculinos, que están más orientados hacia sí mismos y no tan integrados en una red de relaciones (Smith 1987: 12). Por cierto, este hallazgo sobre la autobiografía femenina respecto al habla y el diseño de la communal voice es apoyado por los nuevos resultados de las investigaciones sobre el cerebro, según las cuales las mujeres están mejor interconectadas socialmente, lo que a su vez permite que recuerden mejor y de una manera distinta que los hombres (Davis 1999). También los textos autobiográficos escritos por mujeres se diferencian a menudo de los escritos por hombres por abordar una temática diferente: una temática más bien privada, menos pública (Watson/Smith 1998). ${ }^{10}$

Es evidente que frente a este proceso y los resultados antes esbozados -es decir, el socavamiento del carácter referencial de la autobiografía a favor de lo ficcional, las diferencias en el recuerdo según el género y su ubicación social respectiva-, se debe prestar particular atención a las fotografías incorporadas en los textos autobiográficos. La fotografía -así como finalmente la autobiografía- se consideró durante mucho tiempo un género confiable, referencial. De ahí que quepa preguntar si la fotografía en tanto medio visual debe estabilizar el diseño del Yo precisamente en el momento en que ya no puede ser

9 Veremos eso en el texto de Margo Glantz y, en extremo, en el proyecto autobiográfico de Marjorie Agosín, que dedica varios volúmenes ilustrados con fotografías a la historia de sí misma y la generación de sus padres, abuelos y bisabuelos: Sagrada memoria. Reminiscencias de una niña judía (1994; versión inglesa, 1995: A Cross and a Star: Memoirs of a Jewish Girl in Chile); Always from Somewhere Else: A Memoir of my Chilean Jewish Father (1998); The Alphabet in my Hands: a Writing Life (1999); The Angel of Memory/El ángel de la memoria (2002).

10 En lo que respecta a las prácticas autobiográficas femeninas, Watson/Smith (1992: xiv) ponen de relieve que deben tomarse en consideración las diversas presiones sobre el "Yo" femenino que trata de articularse: no sólo las de género sexual, sino también las de clase social, y su etnicidad. Además, debe considerarse la ubicación del sujeto en la sociedad, su estatus social y su grado de exclusión o inclusión. De ahí que pueda ser sumamente significativa la utilización del género tradicional de la autobiografía. Watson/Smith (1992: xix) la explican con la voluntad de inscribirse en cierta tradición literaria, para prestar así autorización a la propia vida contada. 
estabilizado mediante la escritura, o si propicia, más bien, un proceso dialógico de hibridación entre ambos medios y su respectiva función conjunta en este diseño de la identidad que se refiere más bien a exponer su carácter de construcción.

\section{Autobiografía y fotografía}

De la fotografía y la autobiografía puede decirse que muestran, en cierta medida, una entangled history es decir, una historia dividida y compartida, término acunado por Shalini Randeria. Ambos medios se han ocupado durante largo tiempo del auto-aseguramiento del individuo al presentar el transcurso de su vida y el proceso de la constitución de su identidad.

Además, ambas (la fotografía como sistema de signos icónico y la autobiografía como sistema de signos simbólico, según Peirce) fueron entendidas durante mucho tiempo como medios que reproducían la realidad sin alteraciones, si bien hay diferencias técnicas evidentes: la descripción de la literatura se lleva a cabo a través de un procedimiento mimético lingüístico, mientras que en la fotografía análoga la inscripción directa de un referente en la placa fotográfica es un proceso químico. Eso es lo que Roland Barthes llama el noema de la fotografía: "ça a été", como "littéralement une émanation du référent" (Barthes 1980: 126). No es sino hasta la crisis de la representación -la crisis de una concepción mimética del arte (quizás antes en la fotografía que en la autobiografía)-, cuando aumentan las dudas sobre sus supuestos modos de representación objetiva, así como de su grado de referencialidad, y se dirigirá la atención al carácter constructivo de ambas formas.

En los últimos años, los teóricos de los medios y de los Estudios Visuales se han ocupado de la relación entre las imágenes y el texto. ${ }^{11}$ Para nuestro contexto son relevantes específicamente las investigacio-

11 Straßner (2002: 19) destaca que ambos medios amplían a través de sus características específicas las del otro medio. La información proporcionada por las imágenes puede servir de estructuración y puede crear más coherencia; además, es posible hacer más comprensible el contenido del texto a través de metáforas y analogías. W. J. T. Mitchell opina: "Todas las artes, dicho en pocas palabras, son compuestas, están conformadas por texto e imagen; todos los medios son medios mezclados que combinan diversos códigos, convenciones discursivas, canales y modos sensoriales y cognitivos" (Mitchell 2008: 152; mi traducción, V. D.). 
nes sobre la relación imagen-texto en las (nuevas y tradicionales) autobiografías, que diferencian tres tipos de relación entre ambos medios (Blazejewski 2002).

1. Subordinación de la imagen al texto: a menudo eso significa una mera función ilustradora de la imagen respecto al texto, con la cual se puede incrementar el grado de referencialidad de lo escrito, ilustrarlo y hacerlo parecer (más) verificable: demostrar, por ejemplo, que las personas o situaciones han existido, y de este modo el lector puede hacerse una imagen visual más allá de la écfrasis verbal.

2. Subordinación del texto a la imagen, donde el texto se desarrolla orientándose en las fotografías y el orden que imponen (es el caso de la fotobiografía).

3. Relación de igualdad: Se crea un diálogo entre texto e imagen que abre otro nivel en el diseño de la identidad, con el incremento de una conciencia crítica respecto a los medios y su supuesto grado de referencialidad. La combinación de fotografía y texto también puede, sin embargo, originar un reto y una puesta en duda de la narración y abrir más el proceso de la recepción.

Además, en ambos medios se destaca el aspecto del tratamiento del tiempo y la acentuación de su fragmentación vs. la de su continuidad, ya que ambos sistemas de signos se ocupan del tiempo y de su transcurso. Ambos poseen al fin y al cabo una base estructural fragmentaria más o menos evidente: la fotografía fija determinados -sobresalientes- momentos de la vida de un individuo. Con escenas y episodios significativos recordados por el autor, la autobiografía busca (o puede buscar) transmitir una impresión coherente de su vida, y -a menudopretende encubrir el carácter fragmentario del recuerdo (ese es uno de los aspectos donde difieren la autobiografía tradicional y la nueva: está última destaca más bien lo fragmentario y la imposibilidad de ofrecer una versión coherente de una vida).

La fotografía como técnica que fija determinados momentos constituye pues un recurso mnemotécnico importante para la reconstrucción del pasado y la historia del individuo. Sin embargo, hay que tomar en cuenta que las fotografías pueden desempeñar dos funciones completamente distintas en el proceso de recordar: 
-el desencadenamiento, sustento e incluso corrección de los recuerdos,

-la aniquilación o falsificación de recuerdos a través de la generalización de una determinada versión fotográfica (Blazejewski 2002: 81).

Sin pecar de generalizar demasiado, podemos constatar que las autobiografías -en sentido lato, tanto las tradicionales como las nuevasrecurren a menudo al potencial mnemotécnico de las fotografías. Lo hacen frecuentemente en forma de álbumes de familia para accionar el proceso del recuerdo y re-construcción, y para contar (y auto-asegurarse de) la historia de una vida en forma de momentos, escenas o episodios. Al menos es lo que los textos afirman. Sin embargo, mientras las fotografías no sean reproducidas en el texto, sino descritas en un proceso de écfrasis, se organizan alrededor de una ausencia sin aclarar su grado de imaginación o referencialidad. ${ }^{12}$ De ahí que parezcan similares en su función a otras imágenes de individuos evocadas meramente mediante el proceso de la écfrasis, p.ej., en escenas ante el espejo, como escenas tópicas dentro de la autobiografía para el autoaseguramiento del personaje principal. Con fotografías sólo evocadas en el texto se desarrolla a menudo un juego entre la imaginación, la referencialidad y cuestiones de representación y representabilidad. ${ }^{13}$

Bajo una óptica específicamente mediática existe otra similitud entre la fotografía y la autobiografía: los textos y, en un sentido estrecho, las autobiografias deben ser entendidas como un medio que tiene la función de ofrecerle al sujeto la experiencia de una unidad imagina-

12 P.ej., en el Libro de los recuerdos de Ana María Shua, las fotografías que sirven a los miembros de la familia como punto de partida para reconstituir su pasado en versiones diferentes, solamente se describen. Asimismo, en Poste restante de C. Rimsky, el álbum de fotos, fechado en 1940, sirve "como disparador de un viaje" (Cánovas, en este mismo volumen, p. 238) y de la búsqueda de sus raíces. En Mestizo, novela de Ricardo Feierstein (1994) que relata la búsqueda de identidad de un protagonista judío argentino que sufre de amnesia, se reproducen fotografías de familia como recurso mnemotécnico.

13 Albers (2001: 535). No parece ser casualidad que la fotografía más famosa de uno de los textos teóricos fundamentales sobre la fotografía, La Chambre claire de Roland Barthes, la fotografía de su madre fallecida de niña en el "Jardin d'Hiver" no sea reproducida, sino solamente descrita detenidamente (Barthes 1980: 105-110). Kolesch (1995: 202, n. 43 y 212) interpreta la fotografía como medio de transición, situada a mediación, entre percepciones, imaginaciones y objetos del entorno que abren así un espacio In-between. 
ria. Este tipo de medialidad debe verse como consecuencia de la revolución tipográfica de la Edad Moderna. A lo largo del siglo XVIII se vuelve posible que el sujeto ilustrado se enfoque mediante la escritura y desarrolle la conciencia de sí mismo como resultado de la cultura textual vigente (Schulte-Sasse 2002: 23). A partir del siglo XIX, la fotografía asumió también esta tarea, hasta que, con el surgimiento de las diferentes concepciones del sujeto, que llevan a cabo su descentramiento, ${ }^{14}$ se torna obsoleta también la unidad "imaginaria" del sujeto producida por los medios. Sin embargo, se puede observar que la fotografía (de familia) como medio a menudo sigue desempeñando este papel de asegurar cierta "unidad": una propia historia, una pertenencia a un grupo y, por consiguiente, una identidad colectiva, y eso justamente en tiempos de grandes cambios sociales y de inseguridad ontológica. Así lo destaca Susan Sontag en su ensayo "On Photography" (Sontag [1980]: 14). Después de estas reflexiones teóricas introductorias, podemos observar ahora la relación entre imagen y texto desarrollada en Las genealogías.

\section{Las genealogías de Margo Glantz: espacios abiertos entre imagen y texto}

En Las genealogías, texto publicado en 1981, Margo Glantz, reflexiona sobre su historia familiar. Ahí la autora, nacida en 1930 en la ciudad de México, se ocupa particularmente de su origen como hija de emigrantes judíos de Ucrania, del destierro de ellos y de sus intentos de radicarse en un país desconocido, así como de su propia pertenencia a la nación mexicana. En la primera edición, el texto contiene 19 fotografías de la familia de la autora (así como varios documentos) intercalados en el texto.

Respecto a las fotografías, desde la $1 .^{\mathrm{a}}$ edición de 1981 hasta la $4 .^{\mathrm{a}}$ de 2006, es notorio que hay cierta variación y dinámica, de modo que no podemos hablar de una obra terminada: además de la fotografía de la portada, que varía con cada edición, se agregan nuevas fotografías, se reemplazan otras y se cambia su orden. La edición de 2006 contiene 26 fotografías: desde los abuelos maternos y los padres de jóvenes

14 Hall (2008: 193-198) se refiere a cuatro descentramientos que socavan la idea de un sujeto autónomo, independiente y capaz de actuar: el marxismo, el psicoanálisis, el estructuralismo y el poder del discurso. 
hasta los nietos de la autora. Se trata mayoritariamente de fotografías de estudio, solamente las más recientes son fotografías privadas, menos formales. Con excepción de la edición de 1998, las fotografías no se encuentran concentradas en un solo lugar como álbum, sino distribuidas a lo largo del texto: al inicio, a mediación o al final de los fragmentos textuales, acompañadas respectivamente de un breve pie de imagen. ${ }^{15}$

Pasando por alto las preguntas sobre los motivos de la elección, distribución, sustitución y adición de las fotografías en las ediciones respectivas, me dedicaré a continuación a los efectos que produce en el lector la 4. ${ }^{\mathrm{a}}$ edición de 2006, la más reciente y accesible, mediante la combinación de texto y fotografía. ${ }^{16}$

El texto de Glantz no es una reflexión retrospectiva lineal coherente, sino un esbozo en serie del Yo y de los recuerdos familiares concentrado en la historia de los padres, de su niñez en Ucrania, su emigración y aclimatación en la ciudad de México. Éste, ordenado grosso modo cronológicamente, contiene, además de un prólogo y un epílogo, 74 fragmentos relativamente breves. Sin embargo, las fotografías no están dispuestas sistemáticamente en un orden cronológico preciso, de modo que no representan el transcurso lineal del tiempo. Esto se hace particularmente evidente al final de la obra: las últimas cinco fotografías, no fechadas, producen un salto en el tiempo, y representan, sobre todo, el encuentro de las generaciones. ${ }^{17}$ Así, la organización de las fotografías a lo largo del texto hace evidente que el proceso de recordar no es lineal, sino discontinuo y en saltos.

Además, se ve que el recuerdo y la reconstrucción del pasado y de la historia familiar para sondear los componentes de la identidad cultural, se representan (primeramente) como un acto comunitario oral -

15 Solamente en la 3. a edición de Alfaguara (1998) aparecen las fotografías como álbum al final del libro, debido a que éstas llegaron demasiado tarde a la editorial (Mudrovcic 2003: 55, n. 15).

16 Ésta contiene además un epílogo fechado en 1997, "La (su) nave de inmigrantes", después de la muerte de ambos padres (Glantz 2006: 218-226).

17 "Mi hija Alina y mis nietos Sofía y Bruno" (Glantz 2006: 185), un retrato de la autora sola: "Margo por Liba Taylor" (Glantz 2006: 190), "Mi nieta Sofía y yo" (Glantz 2006: 195), una de su madre con la hija de la autora: "Renata y mi madre" (Glantz 2006: 198), una de la autora de niña con sus padres y su hermana: "Con mis padres en Chapultepec" (Glantz 2006: 205), y la última foto representa a sus hijas de adolescentes: "Alina y Renata, mis hijas" (Glantz 2006: 212). 
grabado en casete por la narradora-protagonista (Glantz 2006: 21) y después puesto por escrito. De ahí, por un lado, su supuesto estilo oral: gran parte de los fragmentos parecen ser transcritos directamente de la grabadora, en estilo directo, donde las voces polifónicas de los padres cuentan sus propias y divergentes versiones de la historia familiar; por otro lado, se mencionan frecuentemente los sonidos que acompañan la énonciation. Este desvelamiento del proceso de creación desempeña la función de, por una parte, evidenciar el proceso de construcción del texto mismo y exponerlo en su materialidad (uno de los rasgos característicos de la nueva autobiografía); por otra, de legitimarlo precisamente como "auténtico".

En cuanto a la relación imagen-texto en Las genealogías, en general se puede constatar que la mayoría de las imágenes no tiene una relación directa y concreta con el texto que las rodea: en primer lugar, hay fotografías que se encuentran desplazadas, ${ }^{18}$ como se ve, por ejemplo, en la fotografía "Hermanos de Barco" (Glantz 2006: 45). En torno a su reproducción, el lector no encuentra ninguna información sobre ellos, sino hasta 24 páginas después (Glantz 2006: 79). A través de la separación espacial de texto e imagen sucede una clara negativa a una subordinación o función sólo ilustrativa de las fotografías. Se destaca, en cambio, su autonomía e independencia y, en cierta medida, se renuncia, a pesar del pie de foto, a una interpretación de la imagen guiada directamente por el texto, en favor de una mayor libertad interpretativa del lector. Además de esta relación desplazada, se puede notar, en segundo lugar, que en la mayoría de los casos no se formula ninguna relación concreta entre el texto y las fotografías. La fotografía de los padres disfrazados de carnaval, situada en el paratexto, delante el prólogo, p.ej., no está comentada (ver abajo). ${ }^{19}$ Queda al lector ubicarla y relacionarla con la trama del texto. A mi modo de ver, esa (no-)relación o relación desplazada entre texto e imagen destaca la autonomía entre ambos y crea al mismo tiempo un diálogo continuo y

18 Este aspecto de una dimensión interpretativa abierta se ve aún reforzado por la falta de fechas en las fotografías (sus pies de imagen) en la edición de 2006, a diferencia de la edición de 1987, incluso cuando son las mismas fotografías reproducidas anteriormente.

19 En la edición de 2006, no fechada; en la edición de 1987 (p. 86), fechada en 1925. 
un juego de diversas afirmaciones que no se pueden reducir a un denominador común. ${ }^{20}$

\subsection{Negociar elementos de identidades: el Yo y la comunidad en el texto y la imagen}

Conforme al título de la obra y en correspondencia con lo dicho más arriba sobre las especificidades de los textos autobiográficos escritos por mujeres, la reflexión en Las genealogías sobre la historia familiar se coloca conscientemente contra la forma tradicional masculina de la autobiografía, que sitúa más bien el foco en un solo individuo. En lugar de eso, se ve la historia de la vida e identidad del individuo femenino como parte y resultado de la historia de los padres, y por tanto como parte de un colectivo, presentada en un acto comunitario oral. Por consiguiente, se utiliza la postura narrativa de la "voz comunal" (communal voice) en el sentido empleado por Lanser en la narratología, es decir, como "una gama de prácticas que articulan una voz colectiva o una colectividad de voces que comparten autoridad narrativa" (Lanser 1992: 21).

Las 26 fotografías en blanco y negro destacan y subrayan esta orientación del texto hacia la comunidad, en tanto que se reproducen numerosas fotografías grupales de miembros familiares en diferentes épocas que representan momentos alegres de fiestas (boda, compromiso, aniversarios) o de otros eventos decisivos para la familia. De este modo, desempeñan el papel de la fotografía mencionado por Susan Sontag: estabilizar al individuo en tiempos de inseguridad ontológica. ${ }^{21}$ Solamente una vez se muestra sola a la autora, solamente tres veces en diferentes edades en el círculo familiar, todas sin fecha. ${ }^{22} \mathrm{El}$

20 Mudrovcic no profundiza en las ricas facetas de la relación entre ambos medios, sino constata que "el texto no parece 'glosar' las fotos y éstas no parecen ilustrar el texto" (Mudrovcic 2003: 54). Además, pasa por alto las fotografías de estudio por ser demasiado formales (Mudrovcic 2003: 54).

21 La "boda del tío Volodia" (Glantz 2006: 111), la "Familia Glantz" (Glantz 2006: 116), los "hermanos de barco" (Glantz 2006: 45), "mi madre en la universidad (Glantz 2006: 43), "mis padres y los tíos panaderos" (2006: 15).

22 La fotografía de la autora sola parece también ser de estudio, porque se indica el nombre de la fotógrafa. Además de las dos fotografías ya mencionadas en la nota 17 (una con su nieta [Glantz 2006: 195], una de niña con sus padres y su hermana en Chapultepec [Glantz 2006: 205]), hay otra de la autora con su hermana Lilly "de niñas" (Glantz 2006: 94). 
planteamiento en el ámbito del discurso narratológico, es decir, de demostrar el Yo anclado en una comunidad, parece ser retomado en el ámbito de las imágenes, sin que podamos hablar de una subordinación de estas últimas al texto.

Esos rasgos aparentemente conocidos y familiares para el lector, de una vida social que se ve en las fotografías -que, a mi parecer, expresan normalidad, alegría, contento-, forman una cara de la medalla: la otra la constituye la historia colectiva de los judíos como marginados, perseguidos, exiliados y -paralelamente a las fotografías tomadas en la niñez de la narradora-, aniquilados por el Holocausto. Estas persecuciones y pogromos no presenciados por la narradora sino por sus padres y abuelos varias veces, sirven de motivo para la emigración y, en cierta manera, se prolongan incluso en México, donde el padre experimenta un ataque antisemita. ${ }^{23}$ Esos momentos no son fijados por la fotografía, sino evocados mediante la escritura. ${ }^{24}$

\subsection{Etnia y religión-tradición judía}

El primer y único elemento de la tradición judía reproducida en una fotografía se observa ya en la cubierta de la $4 .^{a}$ edición (fig. 1): un(a) adolescente con sombrero y chaqueta que parece tener instrumento de viento en la boca que está tocando. En las primeras páginas del libro, se aclara: "niño ortodoxo en una ceremonia religiosa". A través de este recurso se evoca y -decepciona-, a mi parecer, el modo de percepción del lector de reconocer (o desear reconocer) a una joven Glantz,

23 Glantz (2006: 112-115). Mudrovcic ve la doble narración (por parte del padre y la madre) de esa persecución al padre como el punto crucial que organiza el texto (Mudrovcic 2003: 51).

24 La única mención directa del Holocausto en Europa, que a lo largo del texto está presente sin mencionar expresis verbis, se encuentra a principios del cap. XIII, donde la narradora habla de su identificación con las víctimas de los nazis ("se parecían a mí") y su sentimiento de "culpa cotidiana" por no haber experimentado este horror y haber sobrevivido (Glantz 2006: 55). 
que surge quizás de cierta expectativa de ver una fotografía de la autora en la portada. ${ }^{25}$

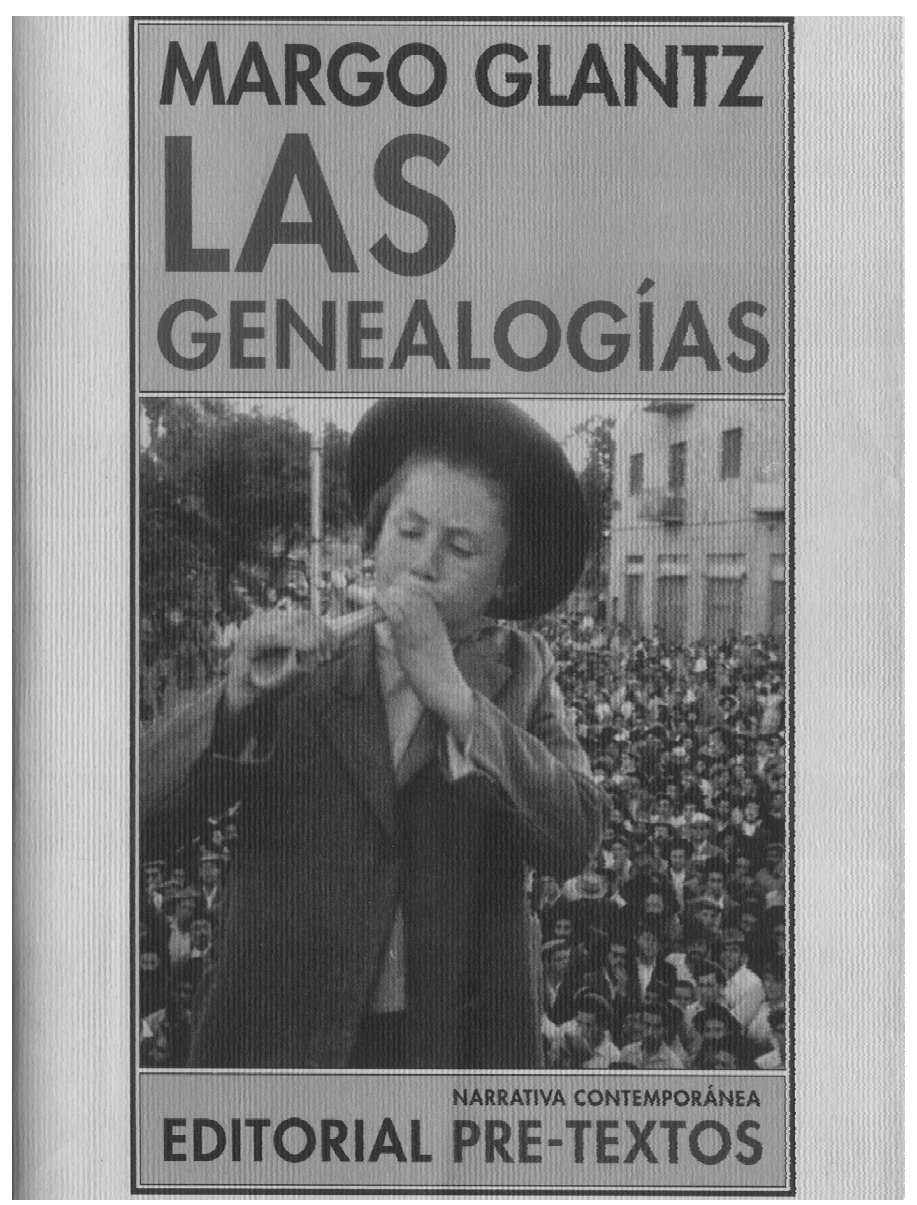

Fig. 1. Glantz (2006, cubierta).

25 Me refiero aquí a un elemento architextual (según Genette) característico, por lo menos, del mercado de libros europeo. Yo diría que las portadas de textos autobiográficos, en sentido lato, llevan casi siempre una imagen del autor, sobre todo, cuando se trata de una persona de la vida pública, para dar información simultáneamente a nivel simbólico e icnográfico y aumentar, por supuesto, el atractivo del producto. La portada de la segunda edición de 1987 tematiza el título del libro "Genealogías" de manera neutra con una fotografía de estudio de una pareja mayor con su hijo, sin una relación judía explícita. 
Esta portada insinúa, a mi parecer, un punto de referencia importante del proyecto de la narradora para determinar su identidad: la tradición ortodoxa judía, e ilustra, por lo tanto, el título de la obra. ${ }^{26}$ El comentario sobre el título se encuentra enseguida en el prólogo, donde la narradora cuestiona su acervo cultural, tanto material como espiritual. Como punto de partida de su proyecto autobiográfico hace una especie de inventario de los objetos que posee $\mathrm{y}$, refiriéndose a su procedencia, que percibe y describe como diversa, afirma lo siguiente:

Yo tengo en mi casa algunas cosas judías, heredadas, un shofar [...]. También tengo un candelabro antiguo [...], pero el candelabro aparece al lado de algunos santos populares, unas réplicas de ídolos prehispánicos [...], unos retablos, unos exvotos, monstruos de Michoacán [...]. Por ellos, y porque pongo árbol de navidad, me dice mi cuñado Abel que no parezco judía, porque los judíos les tienen, como nuestros primos hermanos los árabes, horror a las imágenes.

Y todo es mío y no lo es y parezco judía y no lo parezco y por eso escribo -éstas- mis genealogías (Glantz 2006: 19).

Lo que salta a la vista en esta cita, sobre todo en la afirmación de la última frase y su negación inmediata ("parezco / no parezco"), la noubicación de la narradora, su falta de pertenencia fija. Se trata más bien de una oscilación entre varias posiciones: lo judío, lo cristiano, lo prehispánico y lo nacional. ${ }^{27}$ En términos de la teoría del sujeto se puede decir que la narradora desde el principio se experimenta como sujeto descentrado, fragmentado, incoherente, híbrido, lo que se observa metonímicamente en sus objetos. Esa comprobación, sin embargo, no es algo típica- o exclusivamente judía, sino una característica del sujeto posmoderno (como acabamos de exponer). No obstante, en este texto la autora (a través de su narradora en primera persona) se dedica a su deseo explícito de dilucidar su propio origen, su genealogía y analizar, por consiguiente, los diferentes elementos constitutivos respecto a su identidad cultural: etnia, religión, nación.

26 Además, la fotografía deja vislumbrar un aspecto de género, aspecto importante en la tradición judía (donde algunas ceremonias son destinadas solamente a los varones), pero que no puedo tratar detenidamente en este artículo por razones de espacio (Graff Zivin [2008: 67] lo menciona como factor del sentimiento de exclusión que se deja ver en los textos de Glantz).

27 Mudrovcic lo denomina In-Between (2003: 49). Este posicionamiento de InBetween a punto de redactar el texto se ve matizado por el sentimiento de estar siempre fuera y excluida (Glantz 2006: 182; Dolle 2004: 154). 
Lo que ya me parece bastante significativo en este prólogo, bajo la óptica de este ensayo, es el hecho de que la narradora confronta dos conceptos de identidad: uno esencialista, otro constructivista, al tematizar su actitud y fascinación hacia imágenes ${ }^{28} \mathrm{y}$ evocar un difundido estereotipo de la cultura judía: su (supuesta) hostilidad hacia imágenes de Dios. La narradora menciona un "horror a las imágenes" (Glantz 2006: 19) que, según una fuente oral familiar (las palabras de su cuñado), es propio de los judíos y sus "primos hermanos, los árabes". En el contexto de la cita, este aspecto es reivindicado como supuesta "prueba" de su falta de identidad judía. Esta referencia, no ampliada a lo largo del texto, deja entrever un atributo sumamente importante y controvertido de la identidad judía, entendida como esencialista, en su dimensión de auto- y heteroestereotipo, y, por consiguiente, toca el centro de Las genealogías. Ella alude a la llamada prohibición bíblica de las imágenes del Antiguo Testamento (lo que significa la prohibición de representar a Dios concretamente) como supuesta característica esencial de los judíos. ${ }^{29}$ La narradora constata su otredad respecto a esa actitud estereotipada hacia las imágenes religiosas, y motiva con eso, entre otras cosas, la búsqueda de su origen, sus "genealogías". Es decir, desde el principio del texto se pone en tela de juicio cada pensamiento esencialista en lo que concierne a la formación de la identi-

28 "Me atraen esas viejas fotografías de un abonero lituano, con su barba puntiaguda (propicia a las persecuciones) y su abrigo desmesurado [...]" (Glantz 2006: 16).

29 En un artículo que traza el desarrollo histórico y polifacético de este concepto, Felicitas Heimann-Jelinek ha destacado, sin embargo, que no es tan fácil derivar una supuesta actitud hostil hacia imágenes de Dios por parte de los judíos a lo largo de los siglos. Ella pone de relieve que de una interpretación errónea de la así llamada prohibición bíblica de las imágenes (derivada de varios pasajes del Antiguo Testamento, a saber, Ex 20, 4; Deut 5, 8 y 4, 16-18) ha surgido el prejuicio duradero y falso de una actitud hostil hacia las imágenes en general por parte de los judíos, así como el de la inexistencia de un arte judío (Heimann-Jelinek 2003: 54). No obstante, la autora subraya también que a lo largo del tiempo este estereotipo, según las circunstancias, fue utilizado a favor o en contra de los judíos y su relación con el arte: Immanuel Kant, a su vez, lo ve positivamente en su Kritik der Urteilskraft como expresión suma de la racionalidad judía; en cambio, Hegel lo matiza hacia lo negativo, y Heinrich Heine, poeta alemán judío, parece adoptar este "prejuicio sugestivo" casi en forma de un autoestereotipo (HeimannJelinek 2003: 62). 
dad. $^{30}$ Este aspecto se ve reforzado mediante las fotografías, como veremos más adelante.

\subsection{Nación y narración fundacional}

Otro elemento constitutivo de una identidad cultural es el de "nación", concebida hasta hace poco como una comunidad situada en un territorio bien delimitado. Resulta bastante evidente que ese es un concepto que contrasta -o por lo menos es controvertido- con la auto-concepción del pueblo judío, que hasta la fundación del Estado de Israel en 1948 se consideraba como diaspórico, sin pertenencia y posesión de un territorio nacional. La cuestión de la asimilación a una nación, surgir en ella o resistirse, es uno de los temas discutidos con más intensidad a lo largo de la historia judía. ${ }^{31}$ Resulta sumamente interesante, por lo tanto, el tema de la nación y de la nacionalidad en las fotografías y el texto de Las genealogías.

En cuanto al elemento "nación", con el transcurso de la lectura se hará claro, a través de los recuerdos divergentes de los padres, que México como país de destino para los emigrantes no fue una tierra de promisión, sino algo contingente, debido, en primer lugar, al establecimiento de reglamentaciones más estrictas de las cuotas de inmigración a Estados Unidos, su país de destino deseado originalmente. ${ }^{32}$ En segundo lugar, fue el resultado de otros acontecimientos ocurridos durante el viaje. Pero no se logra destilar la "verdad histórica", es decir la "master-version" del pasado, de modo que hay dos versiones concurrentes expuestas por los padres: según el padre, se debe al miedo a los negros en Cuba, donde primero pensaron quedarse hasta poder emigrar a Estados Unidos: "[...] la noche estaba tan negra, y los negros eran tan negros, con los ojos brillantes y los dientes blancos, tan blancos que me asusté" (Glantz 2006: 80). Ante la versión más sobria de la madre, según la cual ellos siguieron a la mayoría de los emigrantes que iban hasta México, la narradora parece inclinarse por

30 Cabe mencionar aquí la observación hecha por Graff Zivin (2008: 13) de que incluso una identidad concebida como híbrida es entendida como esencialista.

31 Frente a una discusión y literatura abundantísimas al respecto, remito solamente de modo ejemplar al ensayo de Saúl Sosnowski en este mismo volumen, a su ensayo de 1987 y a la rica bibliografía dada en Avni/Bokser-Liwerant/DellaPergola et al. (2011: 761-822).

32 Es la ley Johnson-Reed, como precisa Mudrovcic (2003: 50). 
la versión más poética del padre, cuando concluye lacónicamente: "Ese maniqueísmo espantado fue la causa de mi nacionalidad" (Glantz 2006: 81). ${ }^{33}$ Tenemos aquí una versión de una narración fundacional carente de patetismo e ironizada que recurre a elementos típicos de narraciones fundacionales nacionales: por estar basada en una dicotomía entre los unos y los otros (los negros de Cuba), donde una otredad étnica es percibida como amenazadora, peligrosa de forma esencialista. Lo que hace aquí Margo Glantz en su reconstrucción del pasado es poner al desnudo las narraciones fundacionales de una comunidad en su dimensión psíquica, y más concretamente, tomar en cuenta el miedo como la base de ellas.

Además de la desmitificación de su país de destino como tierra prometida, en este punto queda claro que para Margo Glantz, nacida ella misma en territorio mexicano, una concepción de la identidad nacional como esencialidad resulta inconcebible. Se trata más bien de un factor contingente, arbitrario (toca a todos los grupos de refugiados, exiliados, emigrados, no sólo a los judíos). Sin embargo, llama la atención una pronunciada localización de su propio Yo en la ciudad de México, así como en la historia mexicana y americana, que casi conleva rasgos de un contra-esbozo, contra esa no-localización o arbitrariedad, cuando la narradora imagina ser Colón o Cortés. ${ }^{34}$ Sin embargo, ese contra-esbozo no tiene el objetivo de establecer una identidad esencialista, inalterable, sino que lleva, en el acto de re-actuar a los descubridores y conquistadores, un carácter sumamente performativo, constructivita. ${ }^{35}$

Esto se ve afirmado con más énfasis en el ámbito de la imagen. A este respecto, la primera fotografía actúa de una manera verdaderamente programática, que se encuentra en la página de la dedicatoria,

33 Ya he presentado esta idea en Dolle (2004: 159).

34 "Dos veces en mi vida me he sentido Colón" (Glantz 2006: 161); "Decidirse a tomar por la calzada Ermita-Iztapalapa [...] es casi ser Cortés. Y así me siento, en femenino, quemando mis naves o dándolas al través como precisa Bernal Díaz" (Glantz 2006: 163); la narradora habla también de la imitación del descubridor Colón y del conquistador Cortés por parte de los inmigrantes: "Todo emigrante que viene a América se siente Colón y si viene a México quiere ser Cortés" (Glantz 2006: 130; Dolle 2004: 155).

35 Matizo en cierta medida lo que desarrollé en mi artículo anterior (Dolle 2004: 159-163). 
en la portadilla de la $4 .^{\text {a }}$ edición. ${ }^{36}$ Ésta muestra a los padres de Glantz vestidos para el carnaval (fig. 2).

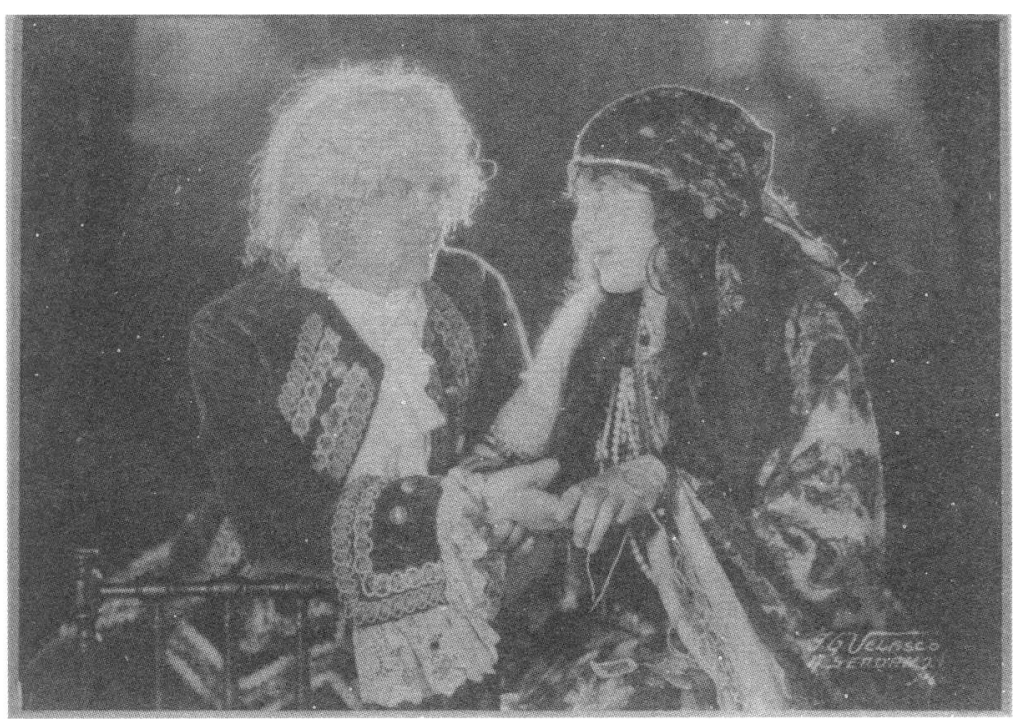

Fig. 2: Mi padre y mi madre de carnaval (Glantz 2006: $\sin$ p.).

Esta imagen constituye, por lo tanto, un marcado contraste respecto a la fotografía de la cubierta, la del niño que participa en una ceremonia religiosa judía. Bajo la perspectiva del proyecto planteado por la narradora de auto-asegurarse de las partes constitutivas de su identidad, interpreto estas dos fotografías como comentario sobre los dos polos opuestos entre los cuales se lleva a cabo la búsqueda de Margo Glantz: el de la tradición invariable y del pasado y el de la performatividad, donde se subraya la dinámica de este proceso nunca acabado.

De un modo semejante, la cuarta fotografía del libro (fig. 3), que presenta al padre en su proceso de mexicanización -con sombrero grande y un cigarrillo en la mano-, podría ser interpretada como "disfraz", como juego carnavalesco e irónico, y no como expresión de adaptación definitiva al nuevo entorno. La puesta en escena con estereotipos de "lo mexicano" tiene, pues, como la fotografía anteriormente mencionada, evidentes rasgos performativos.

36 La edición de 1987 presenta en este lugar una fotografía de familia con el título "Lilly se compromete". 
Desde la portada hasta este punto se abre un espacio semántico que destaca las tensiones entre la tradición judía, el origen y la asimilación a un nuevo entorno o su apropiación a través de una actuación, esta última parecida a la imaginación de los inmigrantes de ser Cortés o Colón (ver arriba). A pesar de su título evidentemente inequívoco: "Mi padre se mexicaniza", mediante las fotografías se evoca la pregunta de si se trata de una asimilación definitiva o más bien de un acto momentáneo (pregunta, a mi modo de ver, no resuelta).

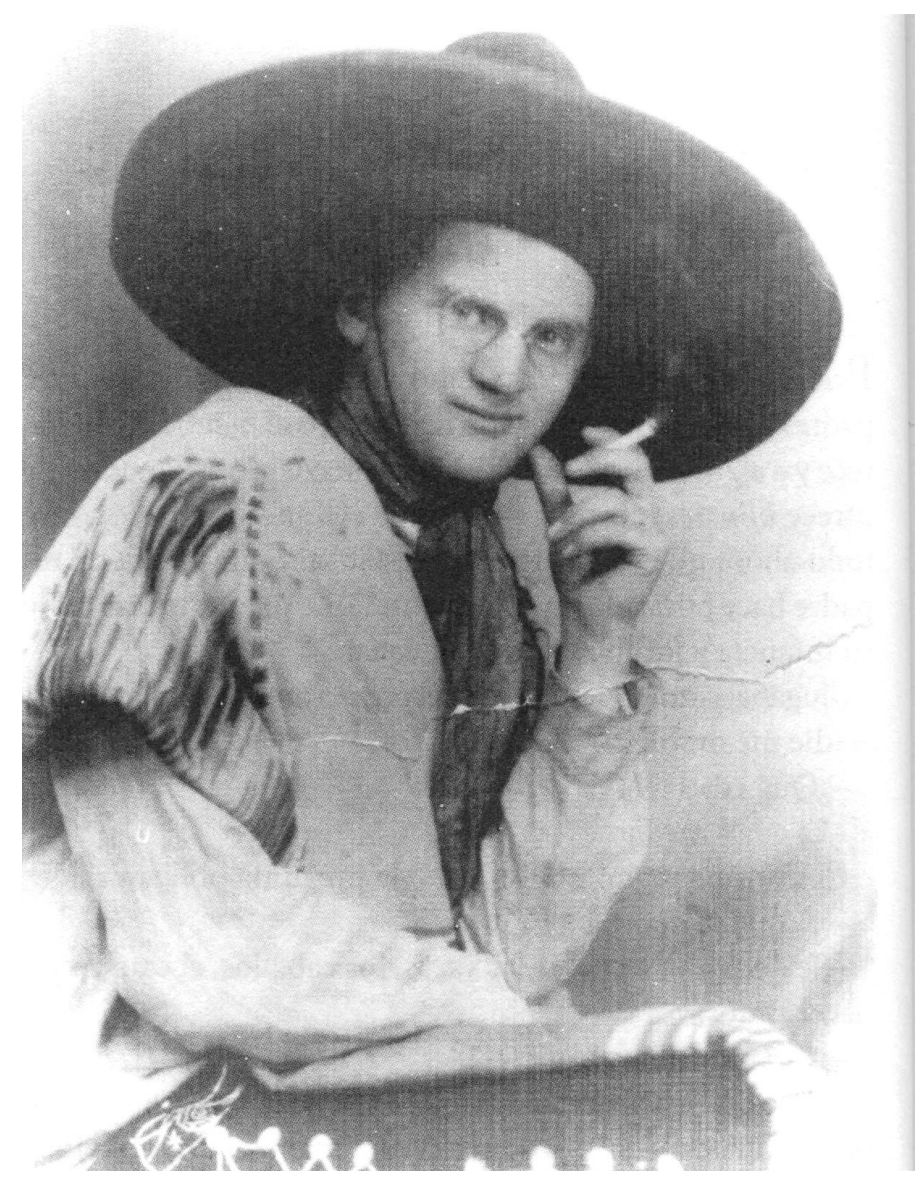

Fig. 3: Mi padre se mexicaniza (Glantz 2006: 22). 


\subsection{El yo polifacético discontinuo: el proceso nunca acabado de autodefinición}

Para terminar, quisiera destacar dos pasajes, en los ámbitos textual y de la imagen, que parecen subrayar, a mi modo de ver, el planteamiento central de la obra respecto a concebir la formación de la identidad como un proceso nunca acabado, sumamente dinámico: me refiero a otra fotografía del padre (fig. 4), así como a un párrafo en el texto que despliega un diálogo con ella.

Ahora bien, esta fotografía, que a primera vista parece una de grupo, si se observa con más detalle se revela como un fotomontaje, como una figura reproducida cinco veces. Este truco, utilizado en los años 20 y 30 del siglo XX no de manera infrecuente en los estudios fotográficos, se encuentra en la tradición surrealista, primer movimiento que entendió la fotografía como arte y no como mimetismo. ${ }^{37}$ Ésta se puede interpretar, conforme a ciertas teorías del sujeto, como referencia a las diversas e irreconciliables facetas del Yo, la cuales no pueden fijarse de manera duradera, sino que más bien forman elementos discontinuos y fragmentados.

37 P.ej., el escritor norteamericano Paul Auster reproduce en su autobiografía de 1988 una fotografía parecida de su padre (Adams 2000: 30). Como modelo sirve una fotografía de Marcel Duchamp de 1917. Ya aquí se socava la supuestamente clara relación indéxica entre realidad y fotografía. Ésta señala anticipadamente hacia las posibilidades de la fotografía digital actual, en la que existen copias sin original (Braun 2002: 122). Una reflexión teórica sobre el medio de la fotografía está inscrita en el mismo texto de Glantz: en el penúltimo capítulo, la narradora presenta una reflexión sobre el modo de proceder de la fotografía, remitiéndose a Barthes, y sobre la pregunta por la artificialidad y el carácter escénico, sobre todo, de las fotografías de estudio, así como por las modas y los modos de la representación (Glantz 2006: 214-217). En este parte la narradora retoma explícitamente algunas características centrales del medio, como la de inmortalizar el pasado (Glantz 2006: 214), y los límites de la representación, teorizando así lo que al principio del texto presentó como una impresión, una fascinación por la fotografía. Al mismo tiempo, al evocar una fotografía (no impresa), la de su padre con un poeta judío, remite a la cercanía entre el proceso de recordamiento y el proceso dinámico, nunca acabado, de creación, de narrar e imaginar: "Sí, mi padre está allí y de esa fotografía maravillosa, que no lo era hasta que Toño me explica su sentido, surgen mil historias que ya no caben en estas páginas" (Glantz 2006: 215). 


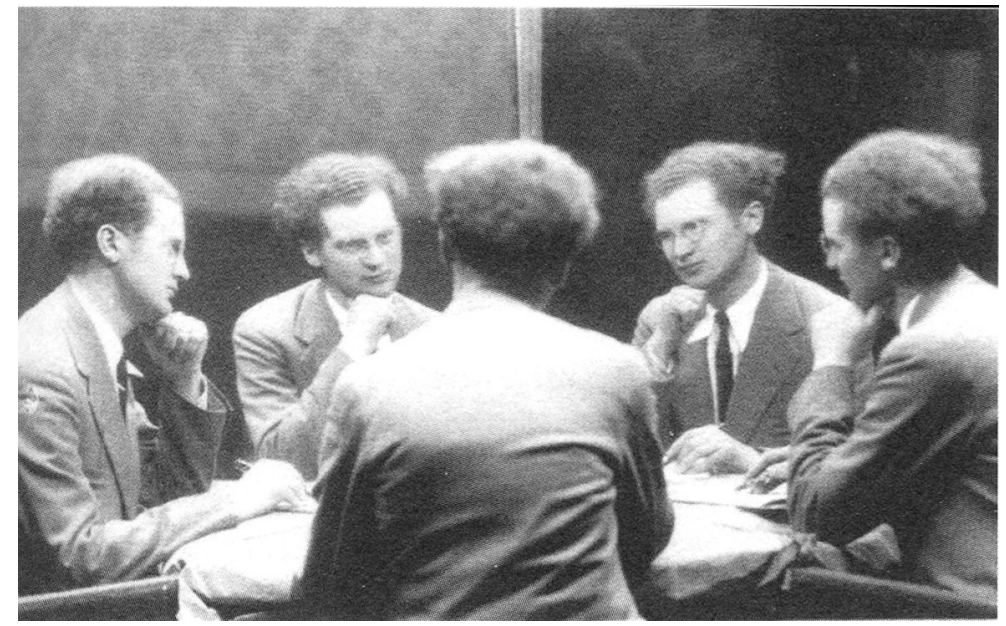

Fig. 4: Narcisismo o melancolía (Glantz 2006: 115).

No quiero tratar aquí el aspecto del narcisismo del padre tematizado en el texto mismo, y el cual es evidente, en cierto sentido, hasta en las fotografías reproducidas de él en Las genealogías. ${ }^{38}$ Ahora quisiera destacar otro punto que me parece igualmente importante: el concepto de identidad concebido como proceso, sin punto final fijo. No solo en el ámbito de la imagen, sino también en el ámbito textual encontramos esta idea: hay un pasaje en el texto que puede verse, así lo interpreto ahora, como réplica dialógica a este fotomontaje del Yo quíntuple del padre, quien representa como poeta y artista un importante punto de

38 Además de estas dos fotografías, la edición de 2006 contiene tres más del padre solo que conllevan un alto grado de auto-estilización. Se intitulan: "Mi padre, el poeta, 1942” (Glantz 2006: 65), “Mi padre en ¿1946?" (Glantz 2006: 104) y “Mi padre escultor" (Glantz 2006: 160). Mudrovcic (2003: 55) destaca, con razón, el papel preponderante del padre en el texto y las fotografías, persona importante para la hija, e interpreta el texto y sobre todo la última fotografía de la edición de 1987 ("Glantz de padre") bajo una óptica freudiana como reconciliación con el padre y su rol en la familia, que realmente nunca cumplió (según Mudrovcic). Además, remite a la interpretación de Freud según la cual el narcisismo tiene su origen en la enfermedad y el dolor físico de una persona, ambos descritos detenidamente en Las genealogías como experiencias fundamentales del padre (Mudrovcic 2003: 52). 
referencia para la hija escritora. ${ }^{39}$ Se trata de la escena donde la narradora cincuentona se mira en el espejo y afirma:

Me visto y me arreglo los ojos [...]. El espejo me triplica, mi perfil es el de un emperador romano. Me choca, como me chocara cuando me descubrí por primera vez de perfil a los dieciséis años. Afortunadamente, me digo, ese perfil es el de un emperador y no el de un esclavo que echaron a los leones (Glantz 2006: 217; cursivas mías, V. D.).

Esta cita, situada en el último capítulo del libro, puede entenderse casi como suma del intento de definir su identidad llevado a cabo en el texto. Además, escenas delante del espejo donde un narrador (autobiográfico) proporciona una écfrasis de su propio cuerpo, o de su rostro, son elementos tópicos de la autobiografía. Aquí, para auto-definirse, la narradora recurre a referencias culturales: primero, "el perfil de un emperador romano", persona que representa poder. Sin embargo, su imaginación no se queda allí, pues más delante sigue el recuerdo del emperador Nerva y su ejecución, de modo que la protagonista prefiere imaginar como punto de referencia el perfil de un mártir cristiano consumido por los leones. ${ }^{40}$ En este pasaje se niega cada punto de referencia de identidad fijo, ya que las referencias culturales no constituyen un sustento sólido de su propia identidad: solamente hay varias identidades reemplazadas en un proceso de de- y reconstrucción permanente, proceso detenido solamente por experiencias corporales (Dolle 2004: 159). Por otra parte, este pasaje también puede leerse como un contra-esbozo humorístico de la tesis lacaniana del estadio del espejo, que presupone la unidad del individuo lograda sólo imaginariamente a través de la mirada en el espejo. ${ }^{41}$

39 Retomo aquí un pasaje de mi artículo (Dolle 2004: 159), donde sitúo el enfoque en los esbozos textuales del cuerpo como objeto fragmentado, sin tomar en cuenta la relación, establecida en el texto, con las fotografías del padre.

40 " [...] acaba de pasar por mi cabeza la imagen del emperador Nerva, cuya cabeza esculpida y guillotinada se ha colocado sobre el cuerpo del emperador Diocleciano, y prefiero tener el perfil de cualquier cristiano comido por los leones y catequizado por el judío Pablo" (Glantz 2006: 217).

41 Mudrovcic (2003: 54) la interpreta como alusión a la exclusión triple de la narradora: "a una cultura, a una familia, a una nación". 


\section{Conclusión}

A pesar de cada intento por parte de la narradora de reconstruir su genealogía definitiva y de auto-asegurarse, a lo largo de la obra se observa como resultado un elemento significativo de performatividad, carnavalización, de-construcción y negociación permanente de la identidad en la figura del padre, así como en la hija misma. La temática y distribución de las fotografías de los padres a lo largo del texto -los padres de carnaval, el padre mexicanizado, el fotomontaje surrealista con la persona quintuplicada- pueden leerse como metáforas de la imposibilidad de construir un Yo duradero, y como indicación al aspecto performativo de la constitución de la identidad. La escena del espejo de la hija, que puede verse como una visualización del Yo con recursos lingüísticos, retoma lúdicamente este rasgo performativo, y muestra también, respecto a las posibilidades de interpretación del propio cuerpo, que no existen atributos fijos a través de referencias culturales.

En Las genealogías de Margo Glantz hemos podido constatar una intensa interacción, prácticamente un diálogo, entre el texto y las fotografías: en lugar de ser solamente una glosa referencial del texto, las fotografías (sobre todo las que comentamos detenidamente) parecen ser una metáfora de la temática del texto: la identidad concebida performativamente. Por medio de la relativa independencia entre las fotografías y el texto explicativo se crea un espacio propio de la ficción, disminuyendo así la función meramente ilustradora de la fotografía. Las fotografías junto con el texto ponen en tela de juicio cada intento de adjudicar al individuo cualquier identidad esencial, sea nacional o étnica, y demuestran al sujeto en su condición postmoderna.

\section{Bibliografía}

Adams, Timothy Dow (2000): Light Writing and Life Writing: Photography in Autobiography. Chapel Hill: University of North Carolina Press.

Agosín, Marjorie (ed.) (1999a): Passion, Memory, Identity. Twentieth-century Latin American Jewish Women Writers. Albuquerque: University of New Mexico Press.

- (1999b): "Introduction". En: Agosín, Marjorie (ed.) (1999a): Passion, Memory, Identity. Twentieth-century Latin American Jewish Women Writers. Albuquerque: University of New Mexico Press, pp. xv-xxx. 
- (2002): Invisible Dreamer, Memory, Judaism, and Human Rights. Santa Fe: Sherman Asher.

Albers, Irene (2001): "Das Fotografische in der Literatur". En: K. Barck et al. (eds.): Ästhetische Grundbegriffe. Tomo 2. Stuttgart/Weimar: Metzler, pp. 534-550.

Amelunxen, Hubertus von (1995): "Photographie und Literatur. Prolegomena zu einer Theoriegeschichte der Photographie". En: Zima, Peter V. (ed.): Literatur intermedial: Musik - Malerei - Photographie - Film. Darmstadt: Wiss. Buchgesellschaft, pp. 209-231.

Avni, Haim/Bokser-Liwerant, Judit/DellaPergola, Sergio et al. (coords.) (2011): Pertenencia y alteridad. Judios en/de América Latina: cuarenta años de cambios. Madrid: Iberoamericana/Frankfurt am Main: Vervuert.

Barthes, Roland (1980): La chambre claire. Note sur la photographie. Paris: Seuil.

Benjamin, Walter ([1931] 1980): "Kleine Geschichte der Photographie". En: Tiedemann, Rolf/Schweppenhäuser, Hermann (eds.): Gesammelte Schriften II-1 (4. ${ }^{\text {a ed. }) . ~ F r a n k f u r t ~ a m ~ M a i n: ~ S u h r k a m p, ~ p p . ~ 368-385 . ~}$

Benstock, Shari (ed.) (1988): The Private Self: Theory and Practice of Women's Autobiographical Writings. Chapel Hill: University of North Carolina Press.

- (1999): "The Female Self Engendered: Autobiographical Writing and Theories of Selfhood". En: Brownley, Martine Watson/Kimmich, Allison B. (eds.): Women and Autobiography. Wilmington: Delware Scholarly Resources, pp. 3-13.

Blazejewski, Susanne (2002): Bild und Text - Photographie in autobiographischer Literatur: M. Duras' L'Amant und M. Ondaatjes Running in the Family. Würzburg: Königshausen \& Neumann.

Braun, Peter (2002): "Fotografie; Fotografie, digitale". En: Schanze, Helmut (ed.): Metzler Lexikon Medientheorie - Medienwissenschaft. Ansätze, Personen, Grundbegriffe. Stuttgart/Weimar: Metzler, pp. 119-122.

Breger, Claudia (2002): "Performativität". En: Kroll, Renate (ed.): Metzler Lexikon Gender Studies Geschlechterforschung. Ansätze, Personen, Grundbegriffe. Stuttgart/Weimar: Metzler, p. 304.

Brodszki, Bella/Schenck, Celeste (1988): "Introduction". En: Brodszki, Bella/ Schenck, Celeste (eds.): Life/Lines. Theorizing Women's Autobiography. Ithaca/ London: Cornell University Press, pp. 1-15.

Butler, Judith (1991): Das Unbehagen der Geschlechter (versión original: Gender Trouble 1990). Frankfurt am Main: Suhrkamp.

Davis, P. J. (1999): “Gender Differences in Autobiographical Memory for Childhood Emotional Experiences”. En: Journal of Personality and Social Psychology, 76, 3, pp. 498-510.

De Toro, Alfonso/Gronemann, Claudia (2004): "Einleitung". En: De Toro, Alfonso/ Gronemann, Claudia (eds.): Autobiographie revisited. Theorie und Praxis neuer autobiographischer Diskurse in der französischen, spanischen und lateinamerikanischen Literatur. Hildesheim: Georg Olms, pp. 7-21. 
Dolle, Verena (2004): "La construcción del sí mismo: memoria cultural e identidad en Las genealogías de Margo Glantz". En: Steckbauer Sonja/Maihold, Günther (eds.): Literatura - historia - politica. Articulando las relaciones entre Europa y América Latina. Madrid: Iberoamericana/Frankfurt am Main: Vervuert, pp. 151162.

- (2010): “A constituição literária do self feminino na diáspora: No exílio, de Elisa Lispector". En: Gronemann, Claudia et al. (eds.): Estrategias autobiográficas en Latinoamérica (Siglos XIX-XXI): géneros - espacios - lenguajes. Hildesheim: Georg Olms, pp. 89-108.

Foster, David William (1999): "Recent Argentine Women Writers of Jewish Decent". En: Agosín, Marjorie (ed.): Passion, Memory, Identity. Twentieth-century Latin American Jewish Women Writers. Albuquerque: University of New Mexico Press, pp. 35-58.

Gasparini, Philippe (2004): Est-il je? Roman autobiographique et autofiction. Paris: Seuil.

Gilmore, Leigh (1994): Autobiographics. A Feminist Theory of Women's Self-Representation. Cornell: University Press.

Glantz, Margo ([1981] $\left.{ }^{4} 2006\right)$ : Las genealogías. Valencia: Pre-Textos.

- ([1981 $]^{2}$ 1987): Las genealogías. México, D.F.: SEP (Lecturas Mexicanas).

Graff Zivin, Erin (2008): The Wandering Signifier. Rhetoric of Jewishness in the Latin American Imagery. Durham/London: Duke University Press.

Gronemann, Claudia et al. (eds.): Estrategias autobiográficas en Latinoamérica (Siglos XIX-XXI): géneros - espacios - lenguajes. Hildesheim: Georg Olms.

Hall, Stuart ([1994] 2008): "Die Frage der kulturellen Identität". En: Hall, Stuart: Rassismus und kulturelle Identität (Ausgewählte Schriften, Tomo 2). Hamburg: Argument, pp. 180-222.

Heimann-Jelinek, Felicitas (2003): “Zum Stereotyp des biblischen Bilderverbots”. En: Golinski, Hans Günter/Hiekisch-Picard, Sepp (eds.): Das Recht des Bildes. Jüdische Perspektiven in der modernen Kunst. Heidelberg: Edition Braus, pp. 5364.

Igel, Regina (1999): "Brazilian Jewish Women Writers at the Crossroads". En: Agosín, Marjorie (1999a): Passion, Memory, Identity. Twentieth-century Latin American Jewish Women Writers. Albuquerque: University of New Mexico Press., pp. 59-84.

- (2000): "Escritores judeus brasileiros. Um percurso em andamento". En: Revista Iberoamericana, 66, 191, pp. 325-338.

Kaplan, Caren (1992): "Resisting Autobiography. Out-Law Genres and Transnational Feminist Subjects”. En: Watson, Julia/Smith, Sidonie: De/colonizing the Subject: The Politics of Gender in Women's Autobiography. Minneapolis: University of Minnesota Press, pp. 115-138.

Kolesch, Doris (1995): "Vom Schreiben und Lesen der Photographie - Bildlichkeit, Textualität und Erinnerung bei Marguerite Duras und Roland Barthes". En: Poetica, 27, pp. 187-214.

Lanser, Susan Sniader (1992): Fictions of Authority. Women Writers and Narrative Voice. Ithaca/London: Cornell University Press. 
Lejeune, Philippe (1975): Le pacte autobiographique. Paris: Seuil.

Man, Paul de (1979): “Autobiography as De-facement”. En: Modern Language Notes, 94, pp. 919-930.

Méaux, Danièle/Vray, Jean-Bernard (dirs.) (2004): Traces photographiques, traces autobiographiques. Saint-Etienne: Publications de l'Université.

Mitchell, W. J. Thomas (2008): "Über den Vergleich hinaus: Bild, Text und Methode". En: Mitchell, W. J. Thomas: Bildtheorie. Frankfurt am Main: Suhrkamp, pp. 136-171. Ed. y epílogo de Gustav Frank (versión original en inglés: "Beyond Comparison: Picture, Text, and Method". En: Mitchell, W. J. Thomas (1994): Picture Theory. Essays on Verbal and Visual Representation. Chicago/London;: University of Chicago Press, pp. 83-107).

Mudrovcic, María Eugenia (2003): “‘Qué diferencia es entre fue y era?’: exilio, fotografía y memoria en Margo Glantz 'Las genealogías'”. En: Hispamérica, 96, pp. 49-56.

Rugg, Linda H. (2000): Picturing Ourselves. Photography and Autobiography. Chicago/London: University Press.

Schabacher, Gabriele (2007): Topik der Referenz. Theorie der Autobiographie, die Funktion, Gattung' und Roland Barthes' Über mich selbst. Würzburg: Königshausen \& Neumann.

Schulte-Sasse, Jochen (2002): "Medien/medial". En: Barck, Karlheinz et al. (eds.): Ästhetische Grundbegriffe. Tomo 4. Stuttgart/Weimar: Metzler, pp. 1-38.

Smith, Sidonie (1987): A Poetics of Women's Autobiography. Marginality and the Fictions of Self-representation. Bloomington: Indiana University Press.

Sontag, Susan ([1980] 2006): Über Fotografie. Frankfurt am Main: Fischer.

Straßner, Erich (2002): Text-Bild-Kommunikation - Bild-Text-Kommunikation. Tübingen: Niemeyer.

Watson, Julia/Sidonie, Smith (eds.) (1992): De/colonizing the Subject: the Politics of Gender in Women's Autobiography. Minneapolis: University of Minnesota Press.

- (1998): Women, Autobiography, Theory: a Reader. Madison: University of Wisconsin Press.

Weingart, Brigitte (2001): "Where is your Rupture? Zum Transfer zwischen Textund Bildtheorie". En: Stefan Andriopoulos et al. (eds.): Die Adresse des Mediums. Köln: Dumont, pp. 136-157.

Welzer, Harald (2002): Das kommunikative Gedächtnis. Eine Theorie der Erinnerung. München: C.H. Beck. 
